\title{
Los impactos de la actividad turística del Parque Arqueológico de San Agustín en las prácticas culturales del Cabildo Indígena Yanacona
}

\author{
Nilver Tovar Ospina \\ Universidad Surcolombiana, Colombia \\ nilvertovar@gmail.com \\ Fredy Tovar Montenegro \\ Universidad Surcolombiana, Colombia \\ fredytovar70@gmail.com
}

\section{Resumen}

El estudio presenta los impactos de la actividad turística del Parque Arqueológico de San Agustín (Huila) en las prácticas culturales del Cabildo Indígena Yanacona. Para ello, se utilizó los relatos de vida como técnica de investigación etnográfica para interpretar la manera en que los miembros de la comunidad Yanacona han percibido los impactos de la actividad turística del citado Parque; seguidamente se cotejó su versión con los administradores de aquel con el fin de analizar sus percepciones y posibles soluciones. Una vez efectuado este proceso de caracterización, se plantearon sugerencias para ambos actores.

Palabras clave: impactos, turismo, Cabildo Indígena Yanacona, prácticas culturales.

\section{Introducción}

El turismo en una actividad con gran apogeo en Colombia en vista que genera inversión importante en distintas actividades económicas como la hotelera, gastronómica, entre otras (Schlüter, 2003). Entre los años 2015 y 2016, informa el Ministerio de Comercio, Industria y Turismo, que el país se ubicó en las cinco primeras posiciones con mayor flujo migratorio con respecto a otros países del continente americano. Sin embargo, los impactos generados por la actividad turística requieren una comprensión con el fin de evaluar las acciones emprendidas en los planes estratégicos de los lugares catalogados como sitios turísticos (en nuestro caso, con respecto a las prácticas culturales del Cabildo Indígena Yanacona, al encontrarse dentro del área de influencia del Parque Arqueológico de San Agustín $(\mathrm{H})$, tal como se puede evidenciar en la siguiente figura).

En la figura 1, se presenta la ubicación del resguardo indígena Yanacona, frente al
Parque Arqueológico de San Agustín (H), evidenciándose de esta manera que las actividades desarrolladas en dicho Parque lo afectan de forma directa al encontrarse dentro de su área de influencia directa.

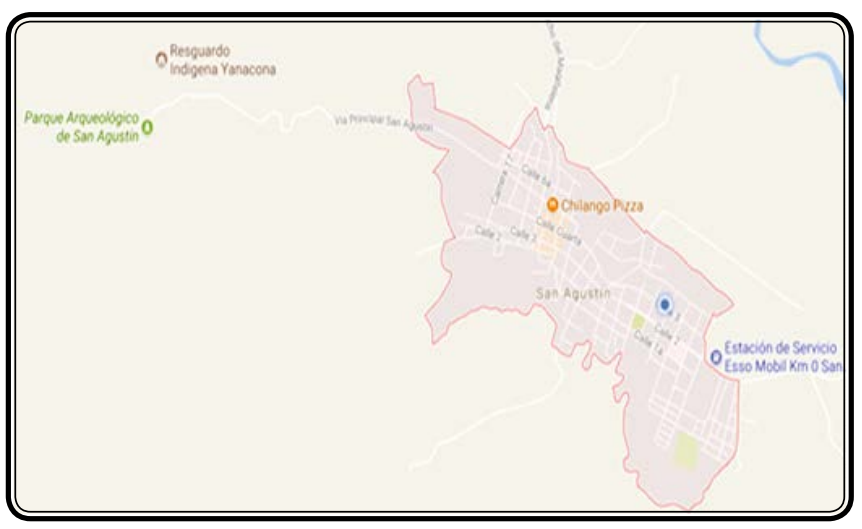

Figura 1. Ubicación del Resguardo Yanacona

Fuente: https://www.google.com.co/maps/place/San +Agustín,+Huila

En vista que los cambios en la sociedad y en el modo de vida de los residentes en 
las áreas de recepción o sitios de llegada de los turistas siempre se dan desde una óptica negativa por su afectación en los sistemas de valores y producción (Restrepo, et al., 2017), los comportamientos, las relaciones familiares y los estilos de vida (Picornell, 2015), es notorio identificar que las comunidades más pobres intentan competir con los escenarios más exigentes que llegan a las zonas donde existe demanda turística (Pérez \& Zizumbo, 2014), como son los hoteles, los supermercados de cadena (Salazar, 2016), restaurantes, etc. (Blázquez, et al., 2011), sin mencionar que otros impactos como los ambientales (Peniche, et al.,2017) que afectan de manera directa el ámbito social y más a las comunidades indígenas que dan la importancia que realmente merece este escenario (Ávila, 2015).

Según Harrison (2011), la actividad turística presenta: a) creciente deseo de productos, modas de consumo y comportamiento inherentes a los turistas. A este fenómeno se le conoce como el efecto ejemplo; b) introducción de actividades no deseadas: prostitución, drogas, inseguridad ciudadana, juegos, entre otros; c) tensiones entre colectivos: problemas derivados de la migración, xenofobia, racismo, entre otros; d) desarrollo de actitudes serviles por parte de los trabajadores turísticos; e) estandarización de roles en el negocio turístico; f) excesiva rapidez en el cambio de las formas de vida locales y g) marginación de la población indígena en determinadas tareas del negocio turístico.

En respuesta a los problemas que genera el turismo a la cultura, la OMT define que los productos turísticos deben ser sostenibles, es decir, "aquellos que son desarrollados en armonía con el medio ambiente, la comunidad y las culturas locales, de forma que estas se conviertan en beneficiarios permanentes, no en victimas del desarrollo turístico" (OMT, 1998; citado por Pereiro, 2013; Maldonado, 2006; Tinoco, 2003).

\section{Materiales y métodos}

El presente estudio es de carácter cualitativo ya que describe y analiza la manera de organizarse y comportarse un grupo social en un determinando entorno (Olabuénaga, 2012). Por lo anterior, este estudio utilizó los relatos de vida como técnica de investigación etnográfica para interpretar la manera en que los miembros de la comunidad objeto de estudio recrean por medio de sus expresiones las prácticas de vida abandonadas, ignoradas o utilizadas para afrontar las dificultades de su medio (Mallimaci \& Béliveau, 2006; García, 1995; Valles, 2000;). Para la aplicación de esta técnica se utilizó la entrevista semiestructurada y se complementó con la observación directa y fotografías de la comunidad en su medio natural (Peña \& Esteban, 2003).

El presente estudio tiene como población a miembros del cabildo indígena Yanacona y los administradores del Parque Arqueológico de San Agustín. Así mismo, recopila la información conforme a los objetivos propuestos y los organiza a partir de una codificación inductiva, la cual se realiza de manera reflexiva y comparativa para identificar en los datos su distinción y semejanza más significativa (Andréu, 2002). A la población objeto de estudio se les realizó 8 entrevistas que estuvieron distribuidas de la siguiente manera: seis para la comunidad Yanacona y dos entrevistas para los administradores del Parque Arqueológico de San Agustín. También se realizó seis observaciones participantes.

Obtenida la información de los actores involucrados en los impactos generados por la actividad turística del Parque se procedió al proceso analítico de las categorías emergentes del trabajo de campo y la revisión bibliográfica. Por ello, se utilizó el software Altas Ti versión 7 (Varguillas, 2006). Las categorías implementadas atienden a un proceso continuo de revisión, reducción e interpretación de los datos obtenidos en cada uno de los instrumentos (Chapman, 2004). A través de las etapas enunciadas anteriormente se identificaron categorías y subcategorías significativas para la comunidad objeto del estudio (ver tabla 1).

En la tabla 1, se presenta en el proceso de análisis de las diferentes categorías a estudiar y de esta manera ilustrarse de las subcategorías y elementos básicos para dar respuesta a los 
impactos generados en las prácticas culturales generadas por el turismo a la comunidad indígena Yanacona.

Tabla 1. Matriz de categorías para el análisis de los impactos de la actividad turística.

\begin{tabular}{|c|c|c|c|}
\hline Categoría & Definición & Subcategorías & $\begin{array}{c}\text { Elementos representativos } \\
\text { para indagación }\end{array}$ \\
\hline \multirow{29}{*}{$\begin{array}{l}\text { Prácticas } \\
\text { culturales }\end{array}$} & \multirow{29}{*}{$\begin{array}{l}\text { Comprende los conocimientos y } \\
\text { actividades arraigadas por individuo } \\
\text { en tanto miembro de una sociedad y } \\
\text { actor de esta (Harris, 2011; citado por } \\
\text { Barrera, 2013). }\end{array}$} & \multirow{4}{*}{ Folclor } & Instrumentos \\
\hline & & & Música \\
\hline & & & Danzas \\
\hline & & & \begin{tabular}{|l|} 
Vestuario \\
\end{tabular} \\
\hline & & \multirow{3}{*}{ Lengua y educación. } & \begin{tabular}{|l|} 
Idioma hablado \\
\end{tabular} \\
\hline & & & \begin{tabular}{|l|} 
Vocabulario \\
\end{tabular} \\
\hline & & & \begin{tabular}{|l|} 
Formación \\
\end{tabular} \\
\hline & & \multirow{4}{*}{ Gastronomía } & Productos \\
\hline & & & Cocción \\
\hline & & & \begin{tabular}{|l|} 
Origen \\
\end{tabular} \\
\hline & & & Bebidas \\
\hline & & \multirow{3}{*}{ Religión } & Creencias \\
\hline & & & Dioses \\
\hline & & & Ofrendas y adoración \\
\hline & & \multirow[b]{2}{*}{ Ritualidad } & Mitos \\
\hline & & & \begin{tabular}{|l} 
Leyendas \\
\end{tabular} \\
\hline & & \multirow{3}{*}{ Medicina } & Productos \\
\hline & & & Origen \\
\hline & & & Uso \\
\hline & & \multirow{3}{*}{ Fiestas } & Celebraciones \\
\hline & & & Tiempo \\
\hline & & & Espacio \\
\hline & & \multirow{3}{*}{ Artesanías } & Objetos \\
\hline & & & Materiales \\
\hline & & & \begin{tabular}{|l|} 
Diseño \\
\end{tabular} \\
\hline & & \multirow[b]{2}{*}{ Arquitectura } & Diseños \\
\hline & & & \begin{tabular}{|l|} 
Materiales \\
\end{tabular} \\
\hline & & \multirow[b]{2}{*}{ Organización } & Familiar \\
\hline & & & Cabildo \\
\hline \multirow[t]{4}{*}{ Impactos } & \multirow{4}{*}{$\begin{array}{l}\text { Refiere a los efectos de la } \\
\text { actividad turística en las prácticas } \\
\text { culturales de los pueblos } \\
\text { indígenas (Tinoco, 2003). }\end{array}$} & \multirow{4}{*}{$\begin{array}{lcr}\text { Impactos } & \text { desde } & \text { la } \\
\text { perspectiva } & \text { de } & \text { los } \\
\text { Yanaconas } & & \\
& & \\
\text { Impactos desde } & \text { la } \\
\text { perspectiva de } & \text { los } \\
\text { administradores } & \text { del } \\
\text { Parque Arqueológico } & \end{array}$} & Impactos positivos \\
\hline & & & Impactos negativos \\
\hline & & & Impactos positivos \\
\hline & & & Impactos negativos \\
\hline $\begin{array}{l}\text { Resolución } \\
\text { de conflictos }\end{array}$ & $\begin{array}{l}\text { Alude a las acciones } \\
\text { implementadas por los actores } \\
\text { para prevenir o reparar los daños } \\
\text { de una actividad realizada por } \\
\text { aquellos. }\end{array}$ & $\begin{array}{ll}\text { Actividades } & \text { de } \\
\text { participación en } & \text { toma de } \\
\text { decisiones } & \end{array}$ & \begin{tabular}{|l|} 
Plan de manejo del Parque \\
desde la perspectiva de los \\
administradores y líderes del \\
Cabildo.
\end{tabular} \\
\hline
\end{tabular}

\section{Resultados}

Los impactos negativos y positivos de la actividad turística del Parque Arqueológico de San Agustín en las prácticas culturales de los Yanaconas, según su perspectiva, son presentados en la tabla 2 y 3 . Los impactos positivos y negativos de la actividad turística

del Parque Arqueológico de San Agustín en las prácticas culturales de los Yanaconas, según la perspectiva de los administradores del Parque, se presentan en la tabla 4 y 5 . Las estrategias implementadas por el Cabildo Indígena Yanacona para su supervivencia con respecto a la actividad turística del Parque Arqueológico de San Agustín se presentan en la tabla 6. Por último, las posibles estrategias de fortalecimiento étnico en el plan del turismo del Parque Arqueológico de San Agustín, según la administración de este, se presentan en la tabla 7 .

En la tabla 2, se presentan a nivel general los diferentes impactos negativos que genera el turismo desde la cosmovisión de los indígenas Yanacona a su comunidad, donde según su percepción de ha afectado a gran escala su lengua nativa, la medicina tradicional, formas de cultivo, música, danzas, etc. Hasta la manera como se percibe el mismo indígena Yanacona frente a la sociedad.

Tabla 2. Impactos negativos de la actividad turística del Parque Arqueológico, según los Yanaconas.

\begin{tabular}{|c|c|}
\hline Hallazgos & Impactos negativos \\
\hline $\begin{array}{l}\text { En la percepción de la comunidad } \\
\text { Yanacona la existencia de la delimitación } \\
\text { del territorio supone un irrespeto a todos } \\
\text { los que son sus moradores, ya que los } \\
\text { territorios son vistos como un referente de } \\
\text { unidad entre el pasado, presente y futuro } \\
\text { de su respeto hacia los espíritus de la } \\
\text { madre naturaleza, su pacha mama. } \\
\text { Por lo anterior se identifica que se valora } \\
\text { como impactos negativos vender el } \\
\text { territorio a personal extranjero, compartir } \\
\text { sus creencias por necesidad económica } \\
\text { (por ej. tal como ocurre con el yagé), } \\
\text { sustituir el trueque por transacciones } \\
\text { económicas para adquirir alimento y } \\
\text { trabajo. } \\
\text { Esta situación ha conllevado a que cada } \\
\text { vez estén más expuestos a la seducción de } \\
\text { otras culturas con respecto a su modo de } \\
\text { vestir, hablar, bailar, utilizar la tecnologia, } \\
\text { etc. Incluso, la manera como son } \\
\text { discriminados en los medios de } \\
\text { comunicación evidencia su poca } \\
\text { participación en estos. } \\
\text { También se encuentran cambios fuertes en } \\
\text { sus prácticas espirituales, ya que realizan } \\
\text { práticas religiosas propias de la cultura } \\
\text { occidental; así mismo la inserción de } \\
\text { metodologias de educación ajenas a su } \\
\text { lengua y prácticas ancestrales (por ej. la } \\
\text { participación del fuego ylas tres tulpas). }\end{array}$ & 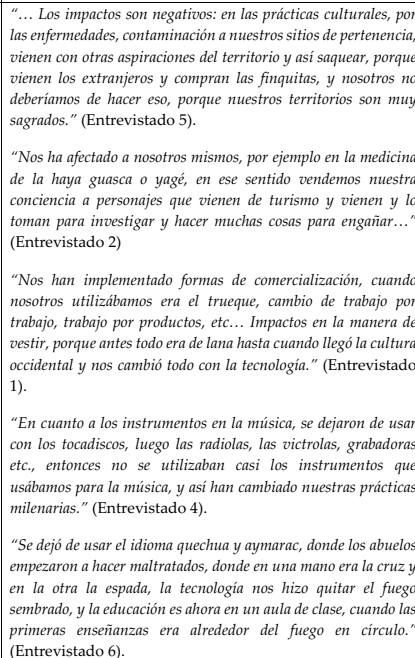 \\
\hline $\begin{array}{l}\text { De otrolado, otro impacto negativo que se } \\
\text { indica refiere a las prátcicas y consumo de } \\
\text { sustancias psicoactivas por algunos de los } \\
\text { extranjeros que llegan al Parque } \\
\text { Arqueológico. } \\
\text { Así mismo, se encuentra que el Parque } \\
\text { tiene un valor espiritual y material para } \\
\text { los pueblos indigenas, pero } \\
\text { desafortunadamente este valor se ha } \\
\text { perdido por el interés económico que se } \\
\text { vivencia desde la administración. Este } \\
\text { interés se soporta en los recursos } \\
\text { destinados a la proteción y el pago por la } \\
\text { actividad turística. }\end{array}$ & $\begin{array}{l}\text { "... Pienso que la drogadicción, por la influencia del turismo... } \\
\text { es como tomarse un café por la mañana, y vienen y les dejan ese } \\
\text { ejemplo a nuestra comunidad y más que todo a los jóvenes que } \\
\text { están en proceso de formación." (Entrevistado } 3 \text { ). } \\
\text { "El Parque Arqueológico tiene un valor espiritual, cultural, } \\
\text { ancestral, y en este momento osolo se tiene por explotación para la } \\
\text { obtención de recursos económicos..." (Entrevistado 2) }\end{array}$ \\
\hline
\end{tabular}




\begin{tabular}{|c|c|}
\hline $\begin{array}{l}\text { De la misma forma, los impactos } \\
\text { negativos son percibidos en su música y } \\
\text { gastronomía, donde cada vez están más } \\
\text { expuestos a cambios en su dieta } \\
\text { alimentaria y ritos sagrados porque los } \\
\text { lugares a los cuales dedican tales } \\
\text { elementos de su identidad se encuentran } \\
\text { modificados por el municipio para } \\
\text { satisfacer las necesidades del turista. De } \\
\text { este modo, el indígena considera que su } \\
\text { identidad fundada en su territorio se } \\
\text { desintegra a medida que más extranjeros } \\
\text { compran sus tierras. } \\
\text { Peor aún, los Yanaconas identifican su } \\
\text { falta de participación sobre su territorio y } \\
\text { cultura dado que encuentra que entidades } \\
\text { como el ICANH poco apoyo ofrecen a su } \\
\text { comunidad. }\end{array}$ & 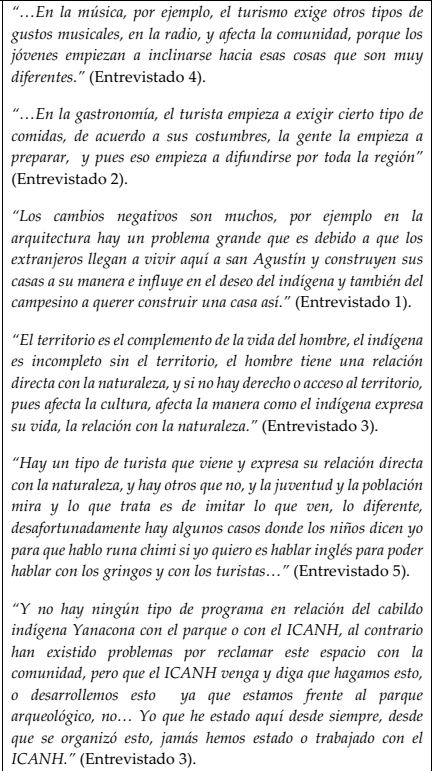 \\
\hline
\end{tabular}

En la tabla 3, se presentan los impactos positivos que han sido considerados según la cosmovision indigena Yanacona, consiguiendo resaltar que según su perspectiva el mas notable ha sido el de una familia Yanacona poder incorporarse en los stand de ventas dentro del parque arqueologico para vender algunas artesanias.

Tabla 3. Impactos positivos de la actividad turística del Parque Arqueológico, según los Yanaconas.

\begin{tabular}{|c|c|}
\hline Hallazgos & Impactos positivos \\
\hline $\begin{array}{l}\text { La comunidad Yanacona no reconocen la existencia de } \\
\text { impactos positivos en sus prácticas culturales, pero sí } \\
\text { en el hecho de permitir la supervivencia de algunas de } \\
\text { las familias cuando estas comercializan sus artesanías } \\
\text { en el Parque Arqueológico de San Agustín. }\end{array}$ & $\begin{array}{l}\text { "...Tal vez algunos positivos, por las ventas de } \\
\text { algunas artesanias, una familia indigena ha podido } \\
\text { vincularse con el Parque para la venta de sus } \\
\text { artesanías." (Entrevistado 2). }\end{array}$ \\
\hline $\begin{array}{l}\text { De otro lado, consideran que un impacto positivo es el } \\
\text { interés de extranjeros por estudiar las prácticas } \\
\text { culturales de la comunidad ya que desarrollan } \\
\text { proyectos de investigación; sin embargo, los Yanaconas } \\
\text { manifiestan que no siempre los ha favorecido dado que } \\
\text { no dejan registro en el Cabildo de las investigaciones } \\
\text { efectuadas. }\end{array}$ & $\begin{array}{l}\text { "... Algo positivo es que en algunos casos los } \\
\text { turistas han querido venir a conocer nuestra } \\
\text { comunidad, nuestra música, nuestra comida, } \\
\text { nuestra organización." (Entrevistado 2). }\end{array}$ \\
\hline
\end{tabular}

En la tabla 4, se dan a conocer los impactos negativos que ha generado los procesos turísticos del Parque Arqueológico del municipio de San Agustín, en las prácticas culturales del cabildo indígena Yanacona según la perspectiva de la administración del parque; resaltando y dejando en evidencia que desde su punto de vista hace falta mayor eficiencia, compromiso y articulación en el Plan de Manejo del Parque Arqueológico de San Agustín con sus necesidades reales.
Tabla 4. Impactos negativos de la actividad turística del Parque Arqueológico, según los administradores del Parque.

\begin{tabular}{|c|c|}
\hline Hallazgos & Impactos negativos \\
\hline $\begin{array}{l}\text { Los administradores consideran que el } \\
\text { Cabildo Yanacona, situados en el } \\
\text { municipio de San Agustín, les hace falta } \\
\text { organización que le permita aprovechar } \\
\text { el turismo del municipio y fortalecer su } \\
\text { visibilización. }\end{array}$ & $\begin{array}{l}\text { "... Yo pienso que el impacto negativo sería la falta de } \\
\text { organización del Cabildo Yanacona para el aprovechamiento de } \\
\text { los turistas que llegan a San Agustinn...Los impactos negativos } \\
\text { que existen son por parte del Cabildo, pero de los turistas que } \\
\text { llegan al Parque no." (Entrevistado 7). } \\
\text { "...Del cabildo no hay nada, entonces pasa desapercibido... Falta } \\
\text { de aprovechamiento del turismo que llega al parque arqueológico, } \\
\text { que no es tanto un turismo de recreación, sino un turismo de } \\
\text { investigación y la cultura."(Entrevistado 8). }\end{array}$ \\
\hline $\begin{array}{l}\text { Ellos señalan que el turismo no genera } \\
\text { impactos negativos, solo positivos, } \\
\text { debido a que los indígenas Yanacona } \\
\text { han podido dar a conocer su practicas } \\
\text { medicinales, su comunidad y las } \\
\text { artesanías, } \\
\text { económicamenter beneficiándose }\end{array}$ & $\begin{array}{l}\text { "... El turismo no ha generado ningún impacto negativo, incluso } \\
\text { se genera son beneficios incluyéndolos a ellos, porque entre ellos } \\
\text { hay artesanos, ellos han dado a mostrar su medicina tradicional, } \\
\text { se ha llevado gente a conocer la maloca, entonces realmente los } \\
\text { impactos son más positivos que negativos, por ejemplo tanto para } \\
\text { ellos como para nosotros se ha beneficiado la economia con el } \\
\text { turismo" (Entrevistado 8). }\end{array}$ \\
\hline $\begin{array}{l}\text { Los administradores señalan que el } \\
\text { ICANH no está funcionando de manera } \\
\text { eficiente con el plan de manejo del } \\
\text { Parque Arqueológico, donde se sugiere } \\
\text { que a veces el plan de manejo genera } \\
\text { incluso más impactos negativos de los } \\
\text { que ya se generan con las practicas } \\
\text { turísticas; por ejemplo, faltar al Decreto } \\
1508 \text { del } 98 \text { donde se dice que no se } \\
\text { deben hacer alteraciones a los paisajes } \\
\text { naturales y culturales. Del mismo modo, } \\
\text { la Ley } 9993 \text {, donde se menciona que no } \\
\text { se deben hacer deforestaciones en } \\
\text { microcuencas, y en la cuenca del Parque } \\
\text { Arqueológico se ha deforestado y existe } \\
\text { contaminacion. Incluso, afectación de la } \\
\text { corriente del agua del lavapatas, } \\
\text { alterando su estado natural. }\end{array}$ & $\begin{array}{l}\text { "...Pero también a pecado el ICANH, a veces genera más } \\
\text { impactos de la manera como lo manejan en este momento como } \\
\text { por ejemplo el destruir una casa, arquitectura antigua que existía } \\
\text { y fue demolida, pegar a base de cementó, el Decreto } 1504 \text { del } 98 \\
\text { donde se dice que no se deben hacer alteraciones a los paisajes } \\
\text { naturales y culturales, como por ejemplo la fuente del lavapatas, } \\
\text { donde se han implementado estructuras que no tienen nada que } \\
\text { ver con el diseño del lavapatas, Ley } 9993 \text { que dice que no se puede } \\
\text { deforestar en una microcuencas y hay contaminación y } \\
\text { deforestación..." (Entrevistado 7). }\end{array}$ \\
\hline
\end{tabular}

En la tabla 5, se muestra los impactos positivos que se generan por las practivas turisticas del Parque Arqueologico del municipio de San Agustin, según la perspectiva de la administracion del mismo, reconociendose como el mas impartante el economico generado por la visita de turistas al Parque creando entradas economicas no solo a este, sino a toda la poblacion del municipio de San Agustin.

Tabla 5. Impactos positivos de la actividad turística del Parque Arqueológico, según los administradores del Parque.

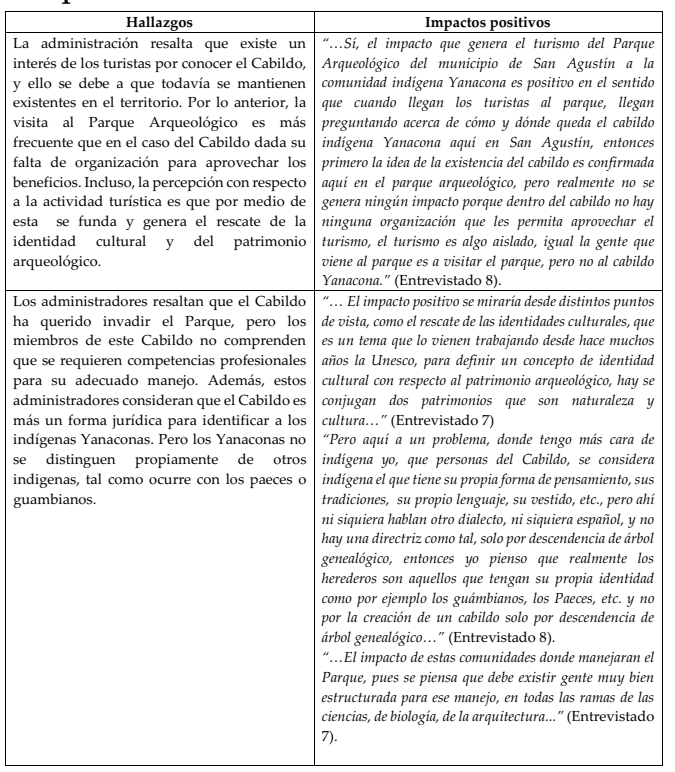


En la tabla 6, se dan a conocer algunas de las estrategias que han sido generadas por los indígenas del cabildo indígena Yanacona como solución a los diferentes impactos que se han generado por las prácticas turísticas que se desarrollan en el Parque Arqueológico de San Agustín, siendo enfocadas en las prácticas culturales.

Tabla 6. Estrategias para la solución de problemas generados por la actividad turística, según los Yanaconas.

\begin{tabular}{|c|c|}
\hline Hallazgos & Estrategias de resolución de conflictos \\
\hline $\begin{array}{l}\text { El Cabildo manifiesta que pese a que no } \\
\text { cuentan con un programa desde su } \\
\text { organización, pero no por su ausencia dejan } \\
\text { de realizar acciones que mitiguen los } \\
\text { impactos que genera el turismo del Parque. } \\
\text { Algunas de estas refieren a indagar las } \\
\text { intenciones de quienes quieren ingresar a su } \\
\text { comunidad, y aquellas quienes difunden el } \\
\text { conocimiento ancentral de su medicina } \\
\text { natural. } \\
\text { Así mismo, la comunidad comparte con otros } \\
\text { indigenas los efectos negativos de } \\
\text { proporcionar sus conocimientos a personas } \\
\text { que buscan la ganancia económica. } \\
\text { Fomentan los encuentros en la Wasi } \\
\text { alrededor de las tres tulpas y el fuego para } \\
\text { que se restituya el conocimiento milenario y } \\
\text { el sentido de pertenencia por los territorios. }\end{array}$ & $\begin{array}{l}\text { "....Nosotros estamos haciendo un estudio, empezando de } \\
\text { cero, diciendo a los de la comunidad que estoy enseñando } \\
\text { estas prácticas medicinales, a que nos cuidemos y no } \\
\text { vendamos de esta manera nuestro conocimiento... Regar } \\
\text { esta información a todas las comunidades indígenas que } \\
\text { nos cuidemos en este sentido, aunque algunos se han } \\
\text { vendido por la parte económica." (Entrevistado 2). } \\
\text { "... Estamos haciendo reconstrucción del conocimiento } \\
\text { por medio de las tres tulpas, que son como las abuelas, } \\
\text { tres piedras en forma de triángulo y se prende el fuego, } \\
\text { Las piedras son milenarias, porque han pasado miles de } \\
\text { generaciones y las piedras han quedado impregnadas de } \\
\text { nuestros ancestros... Estamos implementando medios de } \\
\text { comunicación, para no vender nuestros territorios." } \\
\text { (Entrevistado 1). }\end{array}$ \\
\hline $\begin{array}{l}\text { El Cabildo fomenta en las familias la } \\
\text { importancia de comprender los medios de } \\
\text { comunicación para utilizarlos como } \\
\text { implementos para su resistencia y } \\
\text { apropiación de su identidad cultural. Incluso, } \\
\text { han utilizado las vías de hechos para reclamar } \\
\text { la garantía de sus derechos. }\end{array}$ & $\begin{array}{l}\text { "...Se está concientizando desde la familia y enseñando } \\
\text { las formas de influencia de los medios de comunicación y } \\
\text { cómo manejarlos. También se están haciendo mingas } \\
\text { donde se está trabajando para reconstruir con los } \\
\text { Yanaconas, los Nasas, y nos concentramos alrededor del } \\
\text { fuego para hacer resistencia y rescatar todas las prácticas } \\
\text { y conocimientos que se han ido perdiendo." } \\
\text { (Entrevistado 2). } \\
\text { "...Y nos hemos tomado vías de hecho para exigir } \\
\text { nuestros derechos, que se tenga en cuenta la comunidad, } \\
\text { estamos implementando los medios de comunicación para } \\
\text { lograr hacer la concientización no solo de nosotros como } \\
\text { comunidad sino también de toda la población." } \\
\text { (Entrevistado 5). }\end{array}$ \\
\hline $\begin{array}{l}\text { A través del escenario educativo se } \\
\text { implementa la recuperación de su lengua } \\
\text { originaria, el runa chimi, para que los jóvenes } \\
\text { comprenda los esfuerzos que como } \\
\text { comunidad han tenido que enfrentar desde } \\
\text { sus proceso migratorios. También se } \\
\text { identifica que el Cabildo ha ahorrado del } \\
\text { subsidio que reciben (un dinero) para } \\
\text { reavivar las fiestas nativas de la comunidad } \\
\text { Yanacona. } \\
\text { De igual modo, se incentiva a la comunidad } \\
\text { indigena joven para que se forme } \\
\text { profesionalmente y retornen a su comunidad } \\
\text { para fortalecer su organización y mejorar las } \\
\text { soluciones a las problematicas que viven el } \\
\text { Cabildo. }\end{array}$ & $\begin{array}{l}\text { "... Se están desarrollando estrategias para recuperar } \\
\text { completamente la lengua runa chimi en estos momentos." } \\
\text { (Entrevistado 6). } \\
\text { "...Se implementó un ahorro de recursos para celebrar las } \\
\text { fiestas nativas de la comunidad indígena Yanacona. } \\
\text { También se está implementando la educación y formación } \\
\text { en liderazgo con nuestros conocimientos y nuestro sentir } \\
\text { de comunidad indigena Yanacona." (Entrevistado 1). } \\
\text { "..Se está ayudando a los jóvenes para que vayan y se } \\
\text { preparen profesionalmente, y luego volver a nuestro } \\
\text { territorio para que nos den más fortaleza frente a todas } \\
\text { las problemáticas que hemos vivido y nos ayuden a } \\
\text { nuestro desarrollo." (Entrevistado 3). }\end{array}$ \\
\hline $\begin{array}{l}\text { El Cabildo no ha desarrollado ninguna acción } \\
\text { que mejore su relación con los } \\
\text { administradores del Parque. Tampoco un } \\
\text { programa de identificación de impactos de la } \\
\text { actividad turística que conlleven un plan de } \\
\text { soluciones que mitiguen aquellos. }\end{array}$ & $\begin{array}{l}\text { "... No se ha generado ningún tipo de solución para } \\
\text { mejorar la relación entre personas del parque y las } \\
\text { personas del cabildo... No se han planeado, pensado o } \\
\text { implementado estrategias para la solución de los impactos } \\
\text { que genera el turismo a las prácticas de la comunidad." } \\
\text { (Entrevistado 2). }\end{array}$ \\
\hline $\begin{array}{l}\text { El Cabildo está el programa de la } \\
\text { etnoeducación con el fin de fortalecer y } \\
\text { conservar las practicas Yanaconas. }\end{array}$ & $\begin{array}{l}\text { "... La decisión que ha tomado la comunidad es el } \\
\text { fortalecimiento a la educación, debido a que todas las } \\
\text { comunidades han acordado que la única forma de hacerle } \\
\text { frente a esto, es por medio de la educación, y fortaleciendo } \\
\text { la educación propia..." (Entrevistado 4). }\end{array}$ \\
\hline
\end{tabular}

En la tabla 7 se dan a conocer las estrategias implementadas por la administración del Parque Arqueológico, como manera de solución a los impactos que se generan por el turismo a la comunidad, enfocándonos en las étnicas, siendo San Agustín un pueblo que presenta gran descendencia de comunidades indígenas; donde se puede evidenciar las grandes falencias que presentan los elementos social y cultural en el componente local en el Plan de Manejo desarrollado para dicho Parque.

Tabla 7. Estrategias del Parque Arqueológico para el fortalecimiento étnico, según los administradores del mismo.

\begin{tabular}{|c|c|}
\hline Hallazgos & Estrategias de resolución de conflictos \\
\hline $\begin{array}{l}\text { El ICANH ha planificado actividades } \\
\text { orientadas a la mejora de las } \\
\text { comunidades, sin embargo la difusión } \\
\text { de la información no se ha dado de } \\
\text { forma satisfactoria. Ello ha ocasionado } \\
\text { que la comunidad Yanacona ignore tales } \\
\text { actividades. Del mismo modo, } \\
\text { reconocen que son pocas las actividades } \\
\text { en pro de la comunidad. }\end{array}$ & $\begin{array}{l}\text { "... En ese plan de manejo, el ICANH ha desarrollado en el } \\
\text { componente social actividades incluyendo al cabildo Yanacona, } \\
\text { aunque la información no se ha dado de manera abierta, } \\
\text { entonces solamente han participado los colegios urbanos en } \\
\text { una carrera de observación incluyendo al cabildo Yanacona... } \\
\text { Se tuvo un reconocimiento, en una actividad llamada piedra, } \\
\text { papel y tijera, que también se incluyóos los estudiantes de diez y } \\
\text { once de la comunidad Yanacona." (Entrevistado 7). } \\
\text { "...Se continua hablando del plan de manejo en el componente } \\
\text { ambiental y componente de divulgación, y en esa divulgación } \\
\text { se incluye la existencia del cabildo Yanacona...Y a nivel } \\
\text { general se están haciendo las horas sociales al colegio nacional } \\
\text { y el colegio cooperativo con las actividades del Parque." } \\
\text { (Entrevistado 8). }\end{array}$ \\
\hline $\begin{array}{l}\text { Por lo anterior, los administradores } \\
\text { sugieren que el plan de manejo } \\
\text { desarrollado por el ICANH requiere } \\
\text { mejoras en vista de los muchos errores } \\
\text { que tiene, por ej., mostrar las diferentes } \\
\text { perspectivas sobre los impactos } \\
\text { generados en la comunidad y en el } \\
\text { Parque, entablar diálogos con la } \\
\text { comunidad, rectificar quienes realmente } \\
\text { pertenecen al Cabildo, entre otras. }\end{array}$ & $\begin{array}{l}\text { "... Ellos han sido muy aparte, la comunidad Yanacona, debido } \\
\text { a que estamos en un país muy centralista, se maneja la parte } \\
\text { social, las comunidades, entonces uno mira que ese plan de } \\
\text { manejo del ICANH debe mejorarse, debe tener más } \\
\text { acercamiento con la comunidad, y lo que la comunidad piensa } \\
\text { como tal, ellos tienen errores en el plan de manejo...El ICANH } \\
\text { debería mirar que beneficios y qué necesidades tiene el } \\
\text { agustiniano y tanto comunidades como indigenas, civiles, la } \\
\text { vida de la región es el turismo." (Entrevistado 7). } \\
\text { "El ICANH cuida un poco a los parques que generan dinero, } \\
\text { no por el valor que tiene el patrimonio } \\
\text { cultural...Recomendación: considero que realmente las } \\
\text { conductas de quienes conforman los cabildos sea por los que } \\
\text { tienen su propia lengua, su propia tradición, su propio vestido } \\
\text { y no todo el mundo que quiera entrar ahí, pienso que esa ley } \\
\text { debería volverse a restructurar". (Entrevistado 8). }\end{array}$ \\
\hline
\end{tabular}

\section{Discusión y conclusión}

Si bien el turismo es un fenómeno que surge de los viajes y estancia en ciertos lugares de los no residentes que en ocasiones se ha motivado por el ocio, negocio o actividad académica (Burkart y Medlik, 1981; OMT, 1994; citado por Sancho \& Buhalis, 1998); estos aspectos han hecho que el Parque arqueológico de San Agustín reúna las condiciones necesarias para constituirse en un destino turístico, especialmente por su valor cultural (Santana, 2003). Adicionalmente, dicha actividad turística como ha podido identificarse pueden generar impactos de toda naturaleza (ambiental, sociocultural, económica, etc.); sin embargo, el estudio se orienta en el factor sociocultural de las comunidades indígenas pues concibe que la inmersión en las prácticas ajenas a su cultura puede ocasionar su extinción y pérdida de conocimiento milenario (Tinoco, 2003; Giménez, 1996).

En este sentido, los impactos negativos han sobresalido con respecto aquellos que son positivos, afectando las formas de 
vida, relaciones familiares, conducta moral, expresiones creativas, cultura tradicional, etc. (Picornell, 2015). Ello ha dado lugar paulatinamente a la pérdida de la identidad ancestral en los Yanaconas, especialmente en las generaciones jóvenes, quienes quieren imitar los comportamientos de los turistas puesto que consideran que con ello lograran aprender nuevos idiomas (inglés, francés u otros), viajar, comprar infinidad de cosas, etc. Así mismo, estas generaciones asignan un valor superior a todos los objetos provenientes de la cultura occidental, ocasionando que los productos artesanales pierdan su valor milenario y se constituyen en productos de comercialización.

Ante la situación vivenciada por la comunidad Yanacona se identifica que muchas de las familias han tratado de vender sus predios por el alto valor que han adquirido estos, lo anterior ha hecho sigan en la desigualdad y la polarización social entre miembros de la comunidad y pobladores del municipio de San Agustín. Sumado a esto, la falta de normatividad ha hecho que aquellos sean los más expuestos a abusos de autoridad al tratar de defender sus derechos. Otro aspecto que refuerza la marginación de la comunidad Yanacona refiere al papel de los medios de comunicación (televisión y radio) donde el contenido de la programación está orientado a la adopción de comportamientos occidentales como el entretenimiento, el consumo, entre otros.

A partir de esto, el mensaje para la comunidad Yanacona se orienta cada vez a afirmar que su existencia depende de adoptar tales comportamientos, los cuales ya se reflejan en el cambio de materiales, colores y diseños que utilizan para la venta de sus productos. Del mismo modo, la situación en mención ocurre con sus ritos sagrados y medicina tradicional que han sido comercializados, por ej. el yagé. En este orden de ideas, es necesario revisar e involucrar a distintos actores en la reconstrucción del plan de manejo y procesos del Parque Arqueológico de San Agustín con el fin de diagnosticar y evaluar las acciones y programas vigentes con respecto a los impactos generados. De este modo se podrá conducir al fortalecimiento de prácticas y productos turísticos sostenibles, es decir, prácticas y productos que estén en armonía con el medio ambiente, la comunidad y las culturas locales, de forma que estas se conviertan en beneficiarios permanentes, y no en victimas del desarrollo turístico (OMT, 1998; citado por Pereiro, 2013).

Por este motivo al realizar el diagnóstico de las prácticas tradicionales y actuales del Cabildo es posible proveer un insumo importante tanto para esta comunidad como para la administración del Parque Arqueológico. De esta manera, las iniciativas informales de reconstrucción de su identidad (Piñeres, 2004) y apropiación de los miembros de la comunidad es lenta; incluso, puede derivar en que sus miembros desarrollen actitudes de rechazo a todo comportamiento occidental (Grimson, 2008; citado por Barrera, 2013), desconociendo la importancia del diálogo intercultural (Keesing, 1993; citado por Barrera, 2013).

Adicionalmente, el componente social se ha caracterizado como un fundamento necesario para el desarrollo económico del municipio de ahí que sea necesario caracterizar a otro tipo de grupos que participan informalmente en la actividad turística, pero del mismo modo que la comunidad Yanacona también han sido impactados. Teniendo en cuenta esto, el proceso de revisión, participación y evaluación de los programas del plan de manejo del Parque debe ser en el corto, mediano y largo plazo; por ej. Las vías de hecho efectuadas por la comunidad Yanacona como la creación de una vía para su acceso a su Cabildo ante la falta de apoyo del ICANH para promover, en conjunto con entidades del municipio, una mejora en su calidad de vida. Aún sin apoyo de este ente, otros indígenas de otras comunidades han colaborado en su proceso de reconstrucción histórica.

Por lo mencionado, se sugiere que el ICANH consolide los programas de etnoeducación, ya que esta sería la mejor herramienta que tendría el Cabildo para que sus miembros comprendan los impactos de la actividad turista, recuperen sus saberes tradicionales y aprendan nuevos saberes de forma crítica (Urbano, 2010). 
También fortalecer la comunicación entre el Cabildo Indígena Yanacona y el ICANH para que de esta manera ambos se articulen en la implementación y seguimiento de los programas de etnoeducación y manejo de las TIC, plan de manejo del parque, y de la actividad turística.

\section{Referencias Bibliográficas}

Andréu A., J. A. (2002). Las técnicas de análisis de contenido: una revisión actualizada. Fundación Centro Estudios Andaluces, Universidad de Granada 10 (2): 1-34. Disponible en: <http://public. centrodeestudiosandaluces.es/pdfs/ S200103.pdf

Ávila Romero, A. (2015). Análisis del Turismo alternativo en comunidades indígenas de Chiapas, México. Études caribéennes, (3132). DOI: 10.4000/etudescaribeennes.7601

Barrera, R. (2013). El concepto de la cultura: definiciones, debates y usos sociales. Revista de Clases historia. España. (Consultado el 28 de noviembre de 2017). Disponible en https://dialnet.unirioja.es/servlet/ articulo?co

Blázquez S., M.; Murray M., I. \& Artigues B., A. A. (2011). La balearización global: el capital turístico en la minoración e instrumentación del Estado. Universidad de Alicante. (Consultado el 10 de noviembre de 2017). Disponible en https:// investigacionesturisticas.ua.es/article/ view/2011-n2-la-balearizacion-globalel-capital-turistico-en-la-minoracion-einstrumentacion-del-estado

Burkart, A. J. \& Medlik, S. (1981). Tourism: past, present and future. London: Heinemann.

Chapman, A. (2004). Análisis DOFA y análisis PEST. (Consultado el 30 de octubre de 2017). Disponible en http://www.degerencia. com/articulos.php?artid=544digo $=5173324$

García M., A. V. (1995). Fundamentación teórica y uso de las historias y relatos de vida como técnicas de investigación en Pedagogía Social. Aula: Revista de Pedagogía de la Universidad de Salamanca (7): 41-60.

Giménez, G. (1996). Territorio y cultura. Estudios sobre las culturas contemporáneas, 2(4):9-30.

Harrison, D. (2011). International tourism: cultures and behavior. Annals of Tourism Research 38 (1), 340-342.

Madrid Restrepo, Jorge H., Mariluz Aguilar Castro, León D. Vélez Vargas, y Sandra B. Muriel

Ruíz. 2017. "Riesgo de pérdida de los sistemas de producción agrícola tradicional por la amenaza turística en Occidente Cercano (Antioquia, Colombia)." Cuadernos de Geografía: Revista Colombiana de Geografía 26 (2): 309-325. doi: 10.15446/ rcdg.v26n2.59145

Maldonado, C. (2006). Turismo y comunidades indígenas: Impactos, pautas para autoevaluación y códigos de conducta. International Labour Office. (Consultado el 28 de octubre de 2017). Disponible en http://www.ilo.org/wcmsp5/groups/ public/---ed_emp/---emp_ent/---ifp_seed/ documents/publication/wcms_117521.pdf

Mallimaci, F. \& Béliveau, V. G. (2006). Historias de vida y método biográfico. Estrategias de investigación cualitativa, 1: 23-60.

Olabuénaga, J. I. R. (2012). Metodología de la investigación cualitativa (Vol. 15). Bilbao: Universidad de Deusto.

Peña C., M. \& Esteban G., M. (2003). El estudio de las identidades desde un enfoque cualitativo. La multi-metodología autobiográfica extendida y los talleres lúdico-reflexivos. EMPIRIA. Revista de Metodología de las Ciencias Sociales (26): 175199.

Pereiro, X. (2013). Los efectos del turismo en las culturas indígenas de América Latina/ 
The Effects of Tourism on the Indigenous Cultures of Latin América. Revista Española de Antropología Americana, 43(1): 155-174.

Pérez-Ramírez, C. y Zizumbo-Villarreal, L. (2014). Turismo rural y comunalidad: impactos socioterritoriales en San Juan Atzingo, México. Cuadernos de desarrollo rural, 11(73), 17-38. doi:10.11144/ Javeriana. CDR11-73.trci

Picornell, C. (2015). Los impactos del turismo. Papers de turisme (11): 65-91. (Consultado el 26 de octubre del 2017). Disponible en http://www.papersdeturisme.gva.es/ojs/ index.php/Papers/article/view/395

Picornell, C. (2015). Los impactos del turismo. Papers de turisme (11): 65-91. (Consultado el 26 de octubre del 2017). Disponible en http://www.papersdeturisme.gva.es/ojs/ index.php/Papers/article/view/395

Peniche, S., Laure, A. y Cázares, L. (2017). El impacto ambiental del turismo internacional: caso de La huella de carbono de los vuelos internacionales hacia Puerto Vallarta, Jalisco, México. Investigaciones Turísticas (14), pp. 45-62. https://dx.doi. org/10.14461/INTURI2017.14.03
Salazar, D. (2016). Comportamiento del sector de alimentos y bebidas y los elementos del marketing mix. En la ciudad de Quito. Turismo y Sociedad, XIX, pp. 177-191. DOI: http://dx.doi.org/10.18601/01207555.n19.10

Santana T., A. (2003). Turismo cultural, culturas turísticas. Horizontes antropológicos, 9(20): 31-57.

Schlüter, R. G. R. G. (2003). Turismo y patrimonio gastronómico: una perspectiva. CIET Centro de Investigaciones y Estudios Turísticos. (Consultado el 2 de octubre de 2017). Disponible en http://www. cieturisticos.com.ar/MTC-T04-02.htm

Tinoco, G. (2003). Los impactos del turismo en el Perú. Industrial Data, 6(1):47-60.

Valles, M. S. (2000). Técnicas cualitativas de investigación social. Madrid: Síntesis Editorial.

Varguillas, C. (2006). El uso de ATLAS. ti y la creatividad del investigador en el análisis cualitativo de contenido UPEL. Instituto pedagógico rural el Mácaro. Laurus 12: 4387. 


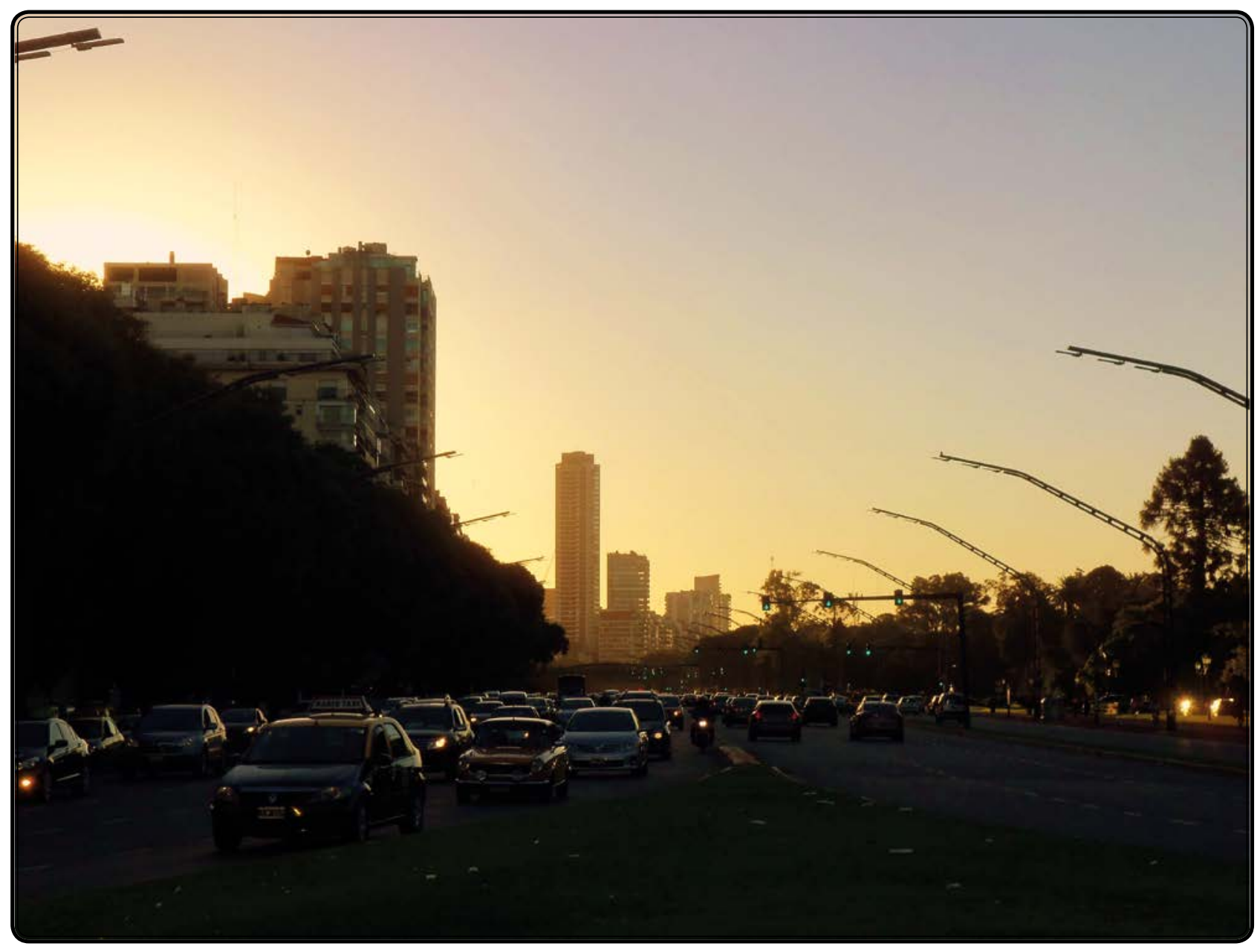

Una marea incontenible. 